Passagens. Revista Internacional de História Política e Cultura Jurídica, Rio de Janeiro: vol. 3 no.1, janeiro-abril 2011, p. 62-76.

\title{
O DEGREDO INTERNO NO BRASIL DO SÉCULO XIX E SUA UTILIZAÇÃO NA OCUPAÇÃO DOS CAMPOS DE GUARAPUAVA
}

\author{
EL DESTIERRO INTERNO EN BRASIL DEL SIGLO XIX Y SU UTILIZACIÓN EN LA \\ OCUPACIÓN DE LOS CAMPOS DE GUARAPUAVA
}

\section{BRAZILIAN'S INTERNAL EXILE IN THE XIX CENTURY AND ITS USE IN THE GUARAPUAVA'S FIELDS OCUPATION}

DOI: $\underline{10.5533 / 1984-2503-20113103}$

Francisco Ferreira Junior

\section{RESUMO}

Este trabalho discute a utilização do degredo como mecanismo de povoamento no Brasil do século XIX através da Carta Régia de 1ํ de Abril de 1809, que ordena a ocupação dos Campos de Guarapuava. São analisadas as razões que dificultaram o povoamento desta localidade, hoje região central do estado do Paraná, as diversas políticas de ocupação presentes na Carta Régia e como o degredo se insere entre elas. O degredo, uma pena característica do Antigo Regime europeu, é analisado neste contexto como uma permanência da cultura jurídico-criminal lusitana no Brasil do século XIX.

Palavras-chave: Degredo, povoamento, cultura jurídica, Paraná.

\section{RESUMEN}

Este trabajo discute la utilización del destierro como mecanismo de poblamiento en Brasil del siglo XIX a través de la Carta Regia de 01 de Abril de 1809, que ordena la ocupación de los Campos de Guarapuava. Son analizadas las razones que dificultaron el poblamiento de esta localidad, hoy región central de la Provincia de Paraná, las diversas políticas de ocupación presentes en la Carta Regia y cómo el destierro se insiere entre ellas. El exilio, una punición característica del Antiguo Régimen europeo, es analizado en este contexto como una permanencia de la cultura jurídico-criminal lusitana en Brasil del siglo XIX.

Palabras-clave: Exilio, poblamiento, cultura jurídica, Paraná. 


\section{ABSTRACT}

This paper discusses the exile's utilization as a mechanism of settlement in Brazil of the 19th century through the Royal Letter of April 1st of 1809, which ordered the Guarapuava's Fields occupation. It is analyzed the reasons which made difficult the settlement of this locality, nowadays the central region of Parana, and the several policies of occupation presented in the Royal Letter and how the exile inserts among them. The exile, a characteristic penalty of the Ancient European Regime, is analyzed in this context as one permanence of the Portuguese juridical/criminal culture in Brazil of the 19th century.

Key Words: Exile, settlement, juridical culture, Paraná.

\section{RÉSUMÉ}

Ce travail discute de l'utilisation du bannissement em tant que mécanisme de peuplement au Brésil du XIXe siècle selon la Lettre Royale du 1er avril 1809, qui commande l'occupation des Champs de Guarapuava. On analyse les raisons qui ont rendu difficile le peuplement de ce site, aujourd'hui région centrale de l'état du Paraná et les plusieurs politiques d'occupation présentes dans la Lettre Royale et comment le bannissement s'y insère. Le bannissement, une peine caractéristique de l'Ancien Régime européen, est analysé dans ce contexte comme une permanence de la culture juridique criminel lusitane au Brésil du XIXe siècle.

Mots clés : Bannissement, peuplement, culture juridique, Paraná.

Algum tempo após a chegada da família real ao Brasil expediu-se um documento que dava ordens para se erigir um povoamento nos Campos de Guarapuava, região central do que viria a ser o estado do Paraná, no sul do Brasil. Trata-se da Carta Régia de $1^{\circ}$ de Abril de 1809 , que contém as ordens reais do príncipe regente $\mathrm{D}$. João VI ao então governador da Capitania de São Paulo, Antonio Joseph da Franca e Horta, sobre como deveria se dar a colonização daqueles campos. É principalmente esse documento que será trabalhado neste artigo, que visa analisar a presença da pena de degredo no Brasil como mecanismo de povoamento compulsório semelhante aos utilizados na Europa desde fins da Idade Média.

Preocupa-nos, num primeiro momento, entender as diferentes políticas de povoamento e os motivos que teriam levado a região a ser eleita como propícia a receber degredados, se convertendo em um dos poucos lugares do país a receber condenados a degredo interno durante o século XIX. Num segundo momento será analisado a forma 
como o degredo aparece na carta e suas relações com a política ocupacional portuguesa do Antigo Regime.

As duas tônicas principais do documento ficam evidentes já em seu título: "Carta Régia - de 1ํ de Abril de 1809 - Approva o plano de povoar os Campos de Guarapuava e de civilisar os índios bárbaros que infestam aquelle território(sic)"”. Essas duas tônicas, povoar e civilizar, se reafirmam durante todo o texto, entre outras preocupações menores.

A comunicação terrestre entre as províncias de São Paulo e Rio Grande do Sul foi um fator importante que concorreu para aumentar o interesse português pela região dos Campos de Guarapuava. Tal comunicação asseguraria um melhor entrosamento entre o centro administrativo do império e o extremo sul do país, entrosamento fundamental para uma unidade administrativa. O trecho seguinte da carta deixa explícita essa preocupação:

Sendo muito útil a comunicação das Capitanias de S. Paulo e Rio Grande pelos campos que vertem para o Uruguay, e passam perto do Paiz das Missões; ordenovos que vos entendais com o governador do Rio Grande, como também Ihe mando directamente significar, para que ambas as capitanias nos seus respectivos territórios e dentro dos limites do Rio das Pelotas, ou pelo alto da serra como dantes era, concorram com os meios necessários para fazer esta estrada quanto antes transitável, de maneira que se consiga assim uma mais fácil communicação das duas Capitanias, e por este meio com esta Capitania que assim communicara com ambas mais facilmente.(sic) ${ }^{2}$

O cuidado com o tratamento dos índios também merece ser destacado:

(...) e portanto considerando que não é conforme aos meus princípios religiosos, e políticos o querer estabelecer a minha autoridade nos Campos de Guarapuava, e território adjacente por meio de mortandades e crueldades contra os Índios, extirpando suas raças, que antes desejo adiantar, por meio da religião e civilisação, até para não ficarem desertos tão dilatados e immensos sertões $(\ldots)(\text { sic })^{3}$

A preocupação para com os índios é comovente. Porém o enfoque principal parece recair menos sobre a preservação dos índios do que sobre a necessidade de garantir a presença do elemento humano, sob o controle português, "para não ficarem desertos tão immensos e dilatados sertões". Isso deixa entrever certa dificuldade para a concentração de pessoas, principalmente brancos, dispostas a povoar a região de Guarapuava. Apenas a presença dos militares da expedição colonizadora não bastaria para assegurar a ocupação do território.

\footnotetext{
1 Coleção das leis do Brasil (1891). Biblioteca da Câmara dos Deputados, Rio de Janeiro: Imprensa Nacional, p.36 a 38.

${ }^{2}$ Ibidem.

${ }^{3}$ Ibidem.
} 
A povoação da região apenas por índios aldeados tampouco interessava a coroa. Daí a necessidade de oferecer alguma benesse as pessoas que eventualmente aceitassem o desafio, e também os riscos, da empreitada colonizadora. Uma dessas benesses consistiria na divisão de alguns terrenos em porções menores de terra distribuídas aos pobres que acompanhassem a expedição. As grandes sesmarias se destinavam aos altos escalões militares envolvidos, bem como a pessoas influentes junto aos poderes administrativos. Dizia o príncipe: "Autorizareis o Commandante para que além das sesmarias concedidas ao Governo possa repartir os terrenos devolutos em proporções pequenas pelos povoadores pobres, pois que esses não teem forças para obterem sesmarias (...)(sic) ${ }^{, 4}$. Ao que parece essa divisão não ficou apenas no papel, mais foi levada a cabo, como indica uma citação em Macedo de que terras a margem do rio Coutinho teriam sido distribuídas aos expedicionários mais pobres. ${ }^{5}$

Mas as benesses não paravam aí. Uma política de isenção de impostos e uma espécie de "mercê" de dívidas junto à fazenda real também aparecem na carta:

Igualmente fareis declarar que toda pessoa que quizer ir povoar os Campos de Guarapuava não será constrangida pelo espaço de seis annos a pagar divida alguma que deva a Fazenda Real, e que pelo tempo de 10 annos não pagará dizimo das terras novas que rotear, nem outro direito parochial senão o que for necessário para 0 mantenimento e trato dos Curas, que alli se estabelecerem.(sic) ${ }^{6}$

Com efeito, as políticas de povoamento tiveram algum sucesso, já que com a tropa de duzentos soldados que formava a expedição colonizadora, vieram também mais cerca de cem pessoas, como coloca Franco ${ }^{7}$.

Para garantir o povoamento e o bom rendimento das obras para a estrada de comunicação com os Campos de Guarapuava, a carta aponta também práticas bem mais sutis de recrutamento compulsório:

(...) ordenareis que faça concorrer os fazendeiros de Coritiba e dos Campos Geraes proporcionalmente as suas forças com alguns escravos para a abertura da estrada, que obrigue também a esse trabalho todas as pessoas que não tiverem estabelecimentos fixos de criação ou lavoura (... $)^{8}$

Deve-se ressaltar que tais práticas parecem ter propiciado um certo terror na região nos primeiros anos da expedição, levado a cabo principalmente pela figura do então

\footnotetext{
${ }^{4}$ Ibidem.

${ }^{5}$ Macedo, F.R. Azevedo (1995). A conquista pacífica de Guarapuava, Curitiba: Fundação Cultural, p.191.

${ }^{6}$ Ibidem.

${ }^{7}$ Franco, Arthur Martins (1943). Diogo Pinto e a conquista de Guarapuava, Curitiba.

8 Ibidem.
} 
comandante Diogo Pinto de Azevedo Portugal ${ }^{9}$. Nesse sentido, tal prática pode ter propiciado um efeito contrário ao desejado, contribuindo para a redução do numero de pessoas dispostas a se estabelecerem, tanto na região de Guarapuava quanto nas adjacentes. De todo modo, o trabalho compulsório, como o recrutamento militar em tropas de linha, era um dispositivo de poder da coroa absolutista e seus mandatários, que sempre implicou estratégias de resistência das classes subalternas. A fuga era uma dessas estratégias. Nada disso invalida as observações a cerca das subjetividades do coronel. A personalidade forte do coronel Azevedo Portugal é lendária, sendo alvo até de discussões bibliográficas nas obras produzidas sobre a conquista de Guarapuava. ${ }^{10}$ É difícil, apenas por um relato, medir o grau de veracidade desse temor aos recrutamentos de Azevedo Portugal, porém tal passagem não pode ser ignorada.

Outra passagem da citação acima possibilita pequena digressão para uma tentativa modesta de análise da mentalidade do homem comum que habitava as regiões centrais do Paraná em princípios do século XIX, que possibilitará o melhor entendimento de pelo menos uma das razões da dificuldade de povoamento dos sertões de Guarapuava. Nos referimos ao medo dos "selvagens".

Em seu artigo de 1956 sobre os primeiros povoadores do Brasil ${ }^{11}$, Emília Viotti da Costa enumera um grande número de lendas sobre o Brasil recém-descoberto que contribuía para gerar o medo no imaginário dos europeus e dificultava o recrutamento de voluntários para o empreendimento da colonização. $O$ medo da longa viagem, que atravessava o oceano e durava meses; o medo das criaturas fantásticas que habitavam as lendas sobre o Novo Mundo; e também o medos dos índios, temidos pelos seus costumes considerados "bárbaros". Era preciso muita coragem para habitar uma terra "onde os pequenos núcleos de povoamento branco eram freqüentemente dizimados pelos ataques dos ferozes canibais 'tão cruéis que ainda não acabavam de matar um homem quando o despedaçavam e comiam.",12

\footnotetext{
9 Ecos desse "terror" podem ser encontrados, de forma quase anedótica, nos relatos do viajante SaintHilaire, que percorreu a região já na década de 1820.

${ }^{10} \mathrm{O}$ primeiro pesquisador que escreveu sobre a história de Guarapuava foi Romário Martins, em seu História do Paraná, de 1899, em que ressalta o gênio truculento de Azevedo Portugal. Em meados do século XX, dois descendentes diretos de Diogo Pinto de Azevedo Portugal escreveram livros sobre a história de Guarapuava onde, contrariando Romário Martins, procuram restaurar a imagem honrada do antepassado. Esses autores são F. C. de Azevedo Macedo, com A conquista Pacífica de Guarapuava, e Arthur Franco, com Diogo Pinto e a conquista de Guarapuava. Para mais informações ver Silva, Walderez P. (1999). Guarapuava: crônicas de uma cidade anunciada. Dissertação (Mestrado em História) UNICENTRO, Guarapuava.

${ }^{11}$ Costa, Emilia Viotti da (1998). "Primeiros povoadores do Brasil: o problema dos degredados". In Revista de pós-graduação em História da UnB, volume 6, números 1 e 2. p. 77 e 78.

${ }^{12}$ Ibidem.
} 
Três séculos depois, para usar a expressão de Capistrano de Abreu, o contexto da colonização de Guarapuava é bem outro. No entanto o medo dos indígenas ainda povoa o imaginário popular, como fica evidente nos relatos de alguns contemporâneos. Em 1817, o padre Aires de Casal coloca o empecilho que parecia ser ao desenvolvimento dos Campos Gerais do Paraná a presença dos índios nos Campos de Guarapuava:

\begin{abstract}
Castro he Villa ainda pequena, e bem situada no lugar, onde o Rio Hyapó atravessa a estrada real; e ornada com uma Igreja Matriz da Invocação de Santo Amaro. Nos arredores acham-se pedras das mais preciozas: e cultivam-se mantimentos. Ao depois de subjugados os Selvagens de Guarapuava, ella deve crescer; e seus extensos contornos passarão a ser semeados de grande números de aldeâs, cujos moradores livres deste flagelo poderão criar muito gado e fazer florescer a Agricultura.(sic) ${ }^{13}$
\end{abstract}

Esse "Selvagens de Guarapuava", posto em iniciais maiúsculas, deixa entrever a fama da região pelos seus habitantes, que ofereciam obstáculos ao florescimento de um "povo civilizado". Além da passagem de Saint-Hilaire, que já demonstra esse medo dos "selvagens" que "infestavam" estes sertões, Ave-Lallemant, que passou pelo Paraná quase trinta anos depois, em 1858, dá exemplos do pavor em passagens do seu relato, quando encontra habitantes locais:

"Não encontraram nenhum bugre?" - perguntou o mais vigoroso entre eles. Dissemos que não. Isso pareceu dar-Ihes prazer. Estranho! Nada - nem a solidão, nem o horror da mata, nem os abismos, nem as cachoeiras, nem os animais ferozes - amedronta esses homens: só a palavra "bugres" os faz estremecer e empalidecer; só pensar neles já os perturba. Vi o assombramento com o espectro dos bugres no Rio Grande, vi-o em Tubarão e no Feixo em Santa Catarina, vi-o em Lajes, em Índios, no rio Bonito, no Trombudo, em toda a parte e de novo na mata do Paraná e no entanto nunca tive ocasião de ver bugres. $E$ não obstante vi homens calmos e corajosos empalidecerem com a simples palavra "bugres" ${ }^{14}$

E ainda: "- O senhor não atiraria no bugre, se o encontrasse? - perguntou o meu hóspede. - Se não me atacasse, não - repliquei eu. O outro abanou a cabeça. - O bugre é um bicho - disse ele. E abandonamos o assunto. Penso que, no íntimo, me deram razão." ${ }^{15}$ Não pensamos que o tenham dado razão.

Na mesma década de 1850, em relato do Engenheiro Hegreville, em viagem de Guarapuava para Palmas, encontramos parecer semelhante:

Eu - Podereis dizer-me senhor, quem foram os que construíram esses ranchos? Condutor - Foram os bugres.

Eu - Sabeis para que fim?

\footnotetext{
${ }^{13}$ Casal, Padre Aires de (1945). Corografia Brasílica, Rio de Janeiro: Imprensa Nacional, p.229. Grifo nosso. ATENCÃO, NÁO TEM NADA GRIFADO NA CITACÃO

${ }_{15}^{14}$ Avé-Lallemant, Robert (1995). 1858, viagem pelo Paraná, Curitiba: Fundação Cultural de Curitiba, p. 30.

${ }^{15}$ Ibidem, p. 35.
} 
Condutor - Sim.

Eu - Quereis contar-mo, se é do vosso gosto?

Condutor - (...) Afim de poderem fazer uma boa colheita de pinhões.(...)

Eu - Oh! Então estou certo de que fizeram uma excelente colheita(...).

Condutor - Elles nada colheram inteiramente. Eu disso os impedi. São animais silvestres que é necessário afugentar para longe de nós. ${ }^{16}$

As diferentes posições políticas perante o tratamento dos indígenas americanos possibilitam a tomada de posições contrárias sobre a animalidade ou humanidade dos indígenas, ou, no campo filosófico, se poderiam chegar ao grau de perfeição do branco. José Bonifácio, por exemplo, era um dos que defendia a perfectibilidade dos índios brasileiros, que já naquele momento compunham as propagandas sobre o Brasil no estrangeiro. A respeito disso, Cunha argumenta: "Até por uma questão de orgulho nacional, a humanidade dos índios era afirmada oficialmente, mas privadamente ou para uso interno do país, no entanto, a idéia da bestialidade, da fereza, em suma da animalidade dos índios, era comumente expressa". E citando um comentário do presidente da província de Minas Gerais, de 1827, em carta ao Visconde de São Leopoldo: "Permita-me v. exa. refletir que de tigres só nascem tigres; de leões, leões se geram; e dos cruéis botocudos (que devoram, e bebem o sangue humano), só pode resultar prole semelhante. ${ }^{17}$

Tais eram as visões sobre o status dos indígenas que circulavam nos meios letrados do século XIX. Mas se nesse meio oferecia-se contestação à visão do índio como animal, isso não parece acontecer entre os sertanejos pobres, que se aventuravam a povoar as regiões mais afastadas, onde se davam cotidianamente os embates entre brancos e índios, como parece evidente nas referências de Ave-Lallemant e Hegreville. Para esses sertanejos, a rotulação do indígena como não humano se coloca como uma questão utilitária, de consciência e de sobrevivência em meio a uma luta que estavam longe de entender.

Esses relatos de viajantes se apresentam em momentos adiantados do século XIX, mas as descrições sobre as primeiras décadas do mesmo século não são muito diferentes. Mota, comentando a já citada carta régia, de novembro de 1808, diz:

A Carta Régia de novembro de 1808 relata ataques generalizados por todo sul do Império, principalmente nos Campos Gerais de Curitiba, de Guarapuava e nos campos das cabeceiras do rio Uruguai. O Príncipe Regente propunha então

\footnotetext{
16 "Relatório do Engenheiro Hégreville sobre a Estrada de Guarapuava e Missões" In Monumenta: Documentação sobre povos indígenas (2001), Vol. 3, № 9, Curitiba, Aos Quatro Ventos. p. 82 e 83.

${ }_{17}$ Cunha, Manuela Carneiro (1992). "Política indigenista no século XIX". In Cunha, Manuela Carneiro (Org.). História dos índios no Brasil, São Paulo: Cia das Letras: Secretaria Municipal de Cultura: FAPESP. p. 136.
} 
guerra contra os índios que matavam cruelmente todos os fazendeiros e proprietários estabelecidos nesses campos. ${ }^{18}$

O documento realmente expõe a preocupação do príncipe para com os "índios denominados bugres", que contribuíam para o despovoamento de toda região central do Paraná, tamanha sua ferocidade.

Claras ficam, nesses relatos, as imagens que a população dita civilizada, da região de Guarapuava, tinha dos índios, pelo menos até meados do século XIX. Na grande maioria das vezes, esse temor era mais fruto da fantasia popular do que da real ameaça que esses índios ofereciam à população branca ou mestiça. Apesar disso, não foram poucos os incidentes com índios acontecidos na região que vieram contribuir para isso. Incidentes como esses, guerras entre as tribos e emboscadas contra os brancos que dizimavam famílias inteiras aconteceram periodicamente até fins do século XIX. O livro de óbitos da Casa Paroquial de Guarapuava, que dá conta de período, está recheado de registros de mortes por assassinatos levados a cabo por indígenas.

Sem falar na enormidade de índios mortos, em quantidade sempre maior que a de brancos, sendo costume dos colonizadores fomentar a inimizade entre os índios aldeados e os ditos "hostis", o que fazia com que os combates se dessem mais entre os próprios índios do que com os portugueses. Nos relatos do presidente da província do Paraná estão presentes alguns pedidos de reforço de tropas para ajudar no combate desses "índios selvagens" quando as revoltas se amiudavam. Isto demonstra também que a "conquista de Guarapuava" não foi tão "pacífica" como querem alguns autores, principalmente no quesito resistência dos índios. ${ }^{19}$

A nossa visão, de homens do século $X X I$, nos permite entender que o que se passava ali era apenas eco da velha resistência do índio à usurpação indiscriminada de territórios que antes lhe pertenciam, mas que agora cada vez mais passavam para o domínio do invasor português. Mas para homem do século XIX, que na expansão para a conquista definitiva dessas terras do sul tinha no seu cotidiano as marcas dessas disputas, é compreensível que essas tribos representassem terror.

Além do mais, é provável que notícias de tragédias como essas se espalhassem de forma rápida, impregnando o imaginário sobre a região e sempre dificultando a possibilidade da vinda de voluntários para o povoamento do local.

O medo dos índios não era o único fator que atrapalhava o projeto de ocupação. A viagem através da Serra da Esperança, na subida para o terceiro planalto paranaense,

\footnotetext{
${ }^{18}$ Mota, Lucio Tadeu (1994). As Guerras dos índios Kaingangs: a história épica dos índios Kaingangs no Paraná (1769-1924), Maringá: EDUEM. p.126.

${ }^{19}$ Me refiro a Macedo, F.R. Azevedo (1995). Op. Cit.
} 
entre os hoje municípios de Castro e Guarapuava, não era fácil no inicio do século XIX. Não havia estradas construídas para esse trajeto. $O$ frio dessa região, que contrastava com o clima predominante no Brasil, também oferecia obstáculo aos colonizadores. A tradição memorialista presente na bibliografia sobre a história da cidade diz que no dia da chegada da Real Expedição Colonizadora aos Campos de Guarapuava, a 17 de Junho de 1810, auge do inverno na Região Sul do Brasil, os cavaleiros "tiveram a impressão de penetrar em um mundo fantástico de cristal, tão grande era a beleza dos campos guarapuavanos cobertos de gelo. A natureza caprichara naquela geada para receber os primeiros povoadores, ${ }^{\prime 20}$. Além do mais a presença de animais selvagens como onças e cobras são ressaltados na maioria dos relatos sobre a região.

\section{Povoar e punir: ordena-se o degredo para Guarapuava}

Retornando a Carta Régia que ordenava a colonização dos Campos de Guarapuava, e mais especificamente, às políticas de povoamento, chegamos, já no final do texto, ao trecho do documento que mais nos interessa: "Igualmente vos ordeno que façais remetter para os Campos de Guarapuava todos os criminosos e criminosas que forem sentenciados a degredo, cumprindo alli todo seu tempo de degredo(sic) ${ }^{21}$. Esse trecho do documento é o que irá converter a cidade de Guarapuava numa espécie de "prisão sem muros", que receberá criminosos durante um longo período do século XIX. Não resta dúvida que essa determinação não estabelece Guarapuava como local para degredo apenas pelas adversidades que o lugar propiciaria aos condenados, mas também pela necessidade e dificuldade que a coroa tinha de ocupação dessas terras, para guarnecimento da fronteira e também comunicação com as províncias do sul.

A distinção, no texto, entre "criminosos e criminosas" também nos possibilita cogitar a dificuldade, novamente consoante com a dos primeiros tempos da colonização do Brasil, de encontrar mulheres portuguesas na região, que possibilitassem casamento e a constituição de famílias dentro dos preceitos da religião católica. Este indício do texto da lei - onde se acentua "as criminosas" - é uma forte demonstração da estratégia de povoamento da Coroa portuguesa nesta região.

\footnotetext{
${ }^{20}$ Marcondes, Gracita G. (1986). Nossa gente conta nossa história. Guarapuava: Governo do Município. p. 130.

${ }^{21}$ Coleção das leis do Brasil (1891), Op. Cit, p. 36 a 38.
} 
Sobre isso, um interessante estudo populacional sobre Guarapuava no século XIX, produzido recentemente e talvez o único até agora, nos possibilita reafirmar a hipótese. ${ }^{22}$ Ao analisar as listas nominativas de habitantes de Guarapuava nos anos de 1828, 1835 e 1840, os dados sobre a distribuição da população entre homens e mulheres são os seguintes. Em 1840 a população de Guarapuava, incluindo agregados, degredados, índios e escravos, dispunha de $54,5 \%$ de homens e $45,5 \%$ de mulheres. Em 1835, os índices estavam em $56,2 \%$ e $43,8 \%$, respectivamente, e no ano de 1828 , mais próximo ao início do povoamento, encontramos $62,8 \%$ de homens e apenas $37,2 \%$ de mulheres. Se há progressão de crescimento da porcentagem de mulheres, que é significativa entre 1828 e 1840, também é verdade que o número de mulheres no início do povoamento era bem pequeno. $O$ baixo número de mulheres é característico nas regiões fronteiriças, principalmente quando a fronteira se alia a perigos, como se acreditava que os índios representavam.

A respeito da presença de mulheres, existe um acontecimento interessante dos primeiros anos da expedição colonizadora que nos parece pertinente analisar aqui. $A$ proibição do contato dos homens da expedição com mulheres indígenas estava expressa já na Carta Régia de 1809: "(...) que ao mesmo commandante seja muito recommendado o vigiar que sua tropa não tenha communicação com as índias (...)” (sic). ${ }^{23}$ Mas, pelos idos de 1810, após os primeiros contatos amistosos entre a Real Expedição e os Índios da região, eis que esses, ávidos por retribuir de alguma forma os muitos presentes recebidos dos portugueses, e como devia ser costume nas tribos, resolveram presentear os expedicionários com algumas mulheres da tribo, para melhor firmarem os laços mútuos de amizade. É claro que o padre Chagas, se certificando das intenções dos visitantes, utilizou de toda sua veemência para dissuadir os sedentos soldados de aceitarem a oferta, que além de desobedecer as ordens régias, ia contra todos os preceitos da religião. A rejeição das ofertas, tomada como ofensa pelos índios, deu azo a um cerco de seis horas ao fortim, depois do qual os índios derrotados se refugiaram na mata. ${ }^{24}$

Também o cuidado com o não contato dos homens da expedição com as índias teria sido um dos motivos da desavença entre o capelão e o comandante a respeito de

\footnotetext{
22 Netto, Fernando F. (2005). População, escravidão e família em Guarapuava no século XIX. Tese (Doutorado em História) - Universidade Federal do Paraná, Curitiba.

${ }^{23}$ Coleção das leis do Brasil, Op. Cit.

24 Lima, Antônio da Chagas (2001). "Memória sobre o descobrimento e colônia de Guarapuava". In Monumenta: Documentação sobre povos indígenas. (2001). Vol. 3, № 9, Curitiba, Aos Quatro Ventos, p. 59 e Silva, Op. Cit, p.30 e 31.
} 
onde se localizaria a futura cidade de Guarapuava, aquele a querendo bem distante do aldeamento indígena, e esse a querendo bem perto, para melhor vigiá-lo. ${ }^{25}$

A despeito do grau de veracidade desses fatos, que apesar de citados em algumas fontes já fazem parte do folclore a respeito do início da cidade, não é difícil deduzir que a maioria dos soldados que para os Campos de Guarapuava vieram não trouxe família, o que contribuiu para a acentuação da ausência de mulheres brancas no local.

Com isso não queremos dizer que o envio de criminalizadas que cogita o documento de povoação tenha sido suficiente para suprir essa ausência, ou mesmo para amenizá-la; muito pelo contrário, o número de degredadas para Guarapuava será ínfimo, como comprovam as fontes. O importante é mostrar em que tipos de práticas se baseiam as estratégias de povoamento presentes no documento, nem todas levadas a termo.

$\mathrm{O}$ teor desse documento, e as estratégias que podemos dele inferir, possibilitam a comparação do movimento de ocupação da região de Guarapuava com uma prática presente em Portugal desde pelo menos o século XII. Nos referimos aos coutos de homiziados .

Para se conceituar os coutos portugueses é interessante a observação dos processos de fins do século XII. Como um país da Europa Ocidental, Portugal viveu um longo período sob o modo de produção de características feudais, de forma que suas terras eram divididas entre senhores que em troca da posse das terras deviam protegêlas e guardá-las em benefício do Rei.

Dessa forma surgiram as honras e os coutos, terras privilegiadas, produto de concessões reais, que eram isentas do pagamento de impostos e onde os direitos reais não prevaleciam ${ }^{26}$. Essas terras eram geralmente asilos eclesiásticos ou possessões da nobreza portuguesa, provenientes de recompensa por trabalhos executados para a coroa; acabavam por tornar-se hereditárias. Ali valia a vontade do senhor, fosse nobre ou eclesiástico. Esse sistema é bastante semelhante às concessões feudais de outros países da Europa Ocidental, que asseguravam o domínio do senhor sobre as terras, a obrigação de protegê-las e o direito de usufruir tanto das terras quanto dos homens conforme the aprouvesse. Com o passar do tempo, a maioria dos direitos feudais vão desaparecendo, e esses territórios passam a ter outra função.

Já no período medieval português, os coutos eram utilizados como lugar de fuga para criminosos do reino, que jurando fidelidade aos senhores das terras obtinham sua proteção contra as leis reais: "Em Portugal, nos fins da Idade Média, certos criminosos

\footnotetext{
${ }^{25}$ Sobre isso ver Silva, Walderez P. (1999). Op. Cit.

${ }^{26}$ Pieroni, Geraldo (2000). Os excluídos do reino: a inquisição portuguesa e o degredo para o Brasil colônia. Brasília: Editora UnB: São Paulo: Imprensa Oficial do Estado.
} 
indesejáveis podiam retirar-se para lugares que lhes eram legalmente reservados: os coutos ou homizios" 27 . Tais criminosos eram conhecidos como homicidas ou homizieiros, designação que se originou dos homicídios, generalizando-se para outros crimes, como relata também Pieroni: "Os termos homicidium e homizio generalizaram-se e passaram a ser associados a delitos graves que implicavam ofensa à honra, como o estupro, o rapto ou agressões físicas que provocassem ferimento."28

Entre os séculos XIII e XV, Portugal viveu um longo período de guerras pela consolidação do Estado Absolutista, visto que seu território, economicamente estratégico, era constantemente ameaçado pelos diversos reinos que formavam a Península Ibérica. Para isso foi necessário o desenvolvimento de políticas para o fortalecimento das guarnições fronteiriças, que não eram poucas naquele país. Porém, muitas das regiões que faziam fronteiras com outros reinos eram áridas, de difícil ocupação. Então, a partir do século XIV, a coroa portuguesa passou a instituir coutos nas regiões de pouco povoamento, "com o propósito de aumentar o povoamento e garantir a defesa do território à custa dos homiziados. ${ }^{29}$ Ou seja, à custa dos criminosos que se refugiavam nesses coutos.

Estima-se que o primeiro Couto instituído para esses fins foi o de Noudar, na fronteira do Algarves, por D. Diniz em 1308. Depois disso, a criação de coutos passou a ser prática corrente em Portugal até o século XVII. Foi inclusive incluída nas ordenações, como mostra o Título CXXIII do Livro V do Código Filipino: "Por se evitarem os danos, que se seguião de os Naturaes destes Reinos andarem homiziados nelles, ou fora delles, e por se povoarem os lugares dos extremos, forão per os Reys nossos antecessores alguns lugares feitos Coutos e privilegiados, segundo em seus privilégios se contem" (sic). ${ }^{30}$ Nota-se, na citação das Ordenações Filipinas, que o caráter de mecanismo de povoação dos coutos não é algo que fica subentendido, pois está explicito no código de leis.

Todos os coutos, quando instituídos pela Coroa para receberem criminosos, passaram a ter regras de funcionamento, o que os diferencia das antigas honras. Essas regras foram se modificando com o passar do tempo. Tais regras também estão presentes nas Ordenações Filipinas: "E quando assi forem, se apresentarão logo aos juízes dos coutos, aos quaes mandamos, que cada hum em seu Julgado faça fazer hum Livro, em que se escrevão pelo Scrivão para isso ordenado todos os homiziados, que ahi

\footnotetext{
${ }^{27}$ Ibidem, p. 24.

28 Ibidem, p. 25.

${ }^{29}$ Moreno, Humberto Baquero (1974). Elementos para o estudo dos coutos de homiziados instituídos pela Coroa, Portugaliae Histórica. Lisboa: Faculdade de Letras da Universidade de Lisboa, v.II.

${ }^{30}$ Ordenações Filipinas, Livro V apud Pierangeli, José Henrique (2001). Códigos penais do Brasil: evolução histórica. $2^{\mathrm{a}}$ Ed. São Paulo: Ed. Revista dos Tribunais.
} 
forem morar, e o dia, em que a elle chegarem (...)" (sic $)^{31}$. Nem todos os criminosos poderiam ser acolhidos: "Os coutos não poderiam albergar os traidores, sodomitas, moedeiros falsos, falsificadores de escrituras, adúlteros e autores de ofensas corporais nas pessoas dos oficiais de justiça."32

Com essa comparação aos coutos não se quer dizer que Guarapuava tenha funcionado como um couto português dos séculos XV ou XVI, uma vez que o próprio contexto histórico era outro. O que queremos é estabelecer algumas semelhanças pela atualização e apropriação, o que demonstra que as práticas e estratégias não desaparecem totalmente através dos séculos, modificando-se e sendo utilizadas quando alguns fatores se assemelham.

Tal foi o clima sobre o qual se deu o principio da ocupação dos Campos de Guarapuava, nas primeiras décadas do século XIX, e que possibilitou que a região se convertesse numa espécie de colônia para degredados. No entanto a menção a degredados, que aparece tão explicitamente na Carta Régia de 1809, desaparece das fontes que chegaram a nós por um período de mais de 10 anos, o que torna difícil uma precisão sobre a presença ou não de degredados nesses primeiros anos. A lei estava posta, mas, quanto tempo passou até começar a ser cumprida?

Não é impossível, embora seja difícil de provar, que os primeiros degredados tenham chegado a Guarapuava juntamente com a própria expedição colonizadora, em 1809. Nenhum documento desse período, além da já comentada Carta, faz menção a eles. Apenas em 1812, cogita-se, das entrelinhas das memórias do padre Chagas, que os primeiros degredados, de origem militar, tenham chegado a Guarapuava:

Pelos fins do anno de 1812 começou a declinar a expedição, e a enfraquecer d'aquelle vigor com que havia começado. A causa também foi que fazendo-se, por Ordem Régia, recolher a seus regimentos os soldados milicianos, foram estes suppridos pelos da ordenança, homens de ínfima plebe, sem estimulo de honra. lam como forçados até descobrirem occasião de se escaparem: uns fugiam em caminho, outros no dia seguinte de sua chegada, outros chegavam miseráveis de roupa e de saúde ..." (sic)

Entre esses "homens de ínfima plebe" que "iam como forçados" até Guarapuava, é provável que estivessem os primeiros degredados a ali pisar. Macedo, em seu livro sobre a conquista de Guarapuava, reafirma tal hipótese, quando fala sobre o recrutamento das tropas que renderiam os primeiros soldados, tropas essas recrutadas pelas autoridades das vilas próximas: "Essas autoridades, sem dúvida, aproveitaram a oportunidade para

\footnotetext{
31 Ibidem.

${ }^{32}$ Moreno, Humberto B. (1974). Op.Cit.

${ }^{33}$ Lima, Antônio da Chagas (2001). Op. Cit, p. 59.
} 
expurgar seus municípios de alguns maus habitantes. Esses foram para Guarapuava como forçados, como degredados. Daí as deserções."34

A guisa de conclusão, observamos que Guarapuava se tratava, no século XIX, de uma região de fronteira, de um território há três séculos disputado entre os colonizadores portugueses e espanhóis. Era uma região de pouco povoamento europeu, que poderia ser encarada como inóspita pelos motivos já citados: índios, clima, dificuldade de acesso. A ocupação da região era fundamental para a guarnição definitiva da fronteira, bem como para a melhor integração dos territórios do agora Império do Brasil. Esses fatores associados possibilitavam à coroa dispor de políticas de povoamento bastante pragmáticas, há muito tempo praticadas na metrópole, como o perdão das dívidas, a isenção dos impostos, e, é claro, o envio de criminosos degredados. São esses os fatores que proporcionam semelhanças entre processos em temporalidades diferentes e em espaços também diferentes, mas que nem por isso deixam de ter associações.

\section{Fontes}

Carta Régia de 1 de Abril de 1809. In Coleção das leis do Brasil, Biblioteca da Câmara dos Deputados, Rio de Janeiro: Imprensa Nacional, 1891, pp. 36 a 38.

\section{Bibliografia}

Avé-Lallemant, Robert (1995). 1858, viagem pelo Paraná, Curitiba: Fundação Cultural de Curitiba.

Casal, Padre Aires de (1945). Corografia Brasílica, Rio de Janeiro: Imprensa Nacional.

Costa, Emilia Viotti da (1998). "Primeiros povoadores do Brasil: o problema dos degredados" In Revista de pós-graduação em História da UnB, volume 6, números 1 e 2.

Franco, Arthur Martins (1943). Diogo Pinto e a conquista de Guarapuava, Curitiba.

Macedo, F.R. Azevedo (1995). A conquista pacífica de Guarapuava, Curitiba: Fundação Cultural.

\footnotetext{
${ }^{34}$ Macedo, F.R. Azevedo (1995). Op. Cit, p.50.
} 
Marcondes, Gracita G (1986). Nossa gente conta nossa história, Guarapuava: Governo do Município.

Monumenta: Documentação sobre povos indígenas (2001), Vol. 3, ํo 9, Curitiba, Aos Quatro Ventos.

Moreno, Humberto Baquero (1974). Elementos para o estudo dos coutos de homiziados instituídos pela Coroa, Portugaliae Histórica. Lisboa: Faculdade de Letras da Universidade de Lisboa, v.ll.

Mota, Lucio Tadeu (1994). As Guerras dos ídios Kaingangs: a história épica dos índios Kaingangs no Paraná (1769-1924), Maringá: EDUEM.

Netto, Fernando F (2005). População, escravidão e família em Guarapuava no século $X I X$. Tese (Doutorado em História) - Universidade Federal do Paraná, Curitiba.

Pieroni, Geraldo (2000). Os excluídos do reino: a inquisição portuguesa e o degredo para o Brasil colônia, Brasília: Editora UnB: São Paulo: Imprensa Oficial do Estado.

. (2003). Banidos: a inquisição e a lista de cristãos novos condenados a viver no Brasil, Rio de Janeiro: Bertrand Brasil. . (2002). Vadios e ciganos, heréticos e bruxas: os degredados no Brasil colônia, Rio de Janeiro: Bertrand Brasil.

Saint-Hilaire, Auguste de (1995). Viagem pela Comarca de Curitiba, Curitiba, Fundação Cultural.

Recebido para publicação em março de 2010. 